\title{
Proposta didática para o curso de licenciatura em educação física: aprendizagem baseada em casos
}

Andreia Cristina Metzner'

\begin{abstract}
Resumo
0 presente artigo tem como tema central a aprendizagem baseada em casos, também conhecida por estudo de casos. 0 objetivo deste estudo é apresentar uma proposta de trabalho implementada em um curso de licenciatura em educação física e estruturada a partir de um caso específico para a área escolar. A metodologia utilizada é de natureza qualitativa e do tipo pesquisa de campo. Participaram do estudo 25 alunos do último ano do curso de licenciatura em educação física pertencentes a uma instituição particular de ensino superior, localizada no interior do estado de São Paulo. As disciplinas selecionadas para o desenvolvimento das ações foram: metodologia da educação física na educação básica, seminário de conclusão de curso e estágio supervisionado. Os resultados da pesquisa apontam que a utilização de casos no curso de educação física promove tanto para o professor quanto para os alunos resultados positivos e necessários para a sua atuação profissional. Acredita-se que, quando a docência é desenvolvida de forma comprometida e a partir de uma prática pedagógica crítica e reflexiva, por meio de desafios instigantes, tanto o professor quanto os alunos alcançam resultados positivos. Para isso, o professor precisa desvencilhar-se da rotina e da zona de conforto propiciada pelas aulas expositivas e enraizadas pelas metodologias tradicionais.
\end{abstract}

\section{Palavras-chave}

Educação física - Aprendizagem baseada em casos Ensino superior. 


\title{
A teaching proposal implemented in an undergraduate Physical Education program: case-based learning
}

Andreia Cristina Metzner'

\begin{abstract}
This article focuses on Case-based learning, also known as case study. the aim of this study is to present a work proposal implemented in an undergraduate Physical Education program and structured from a specific case for the education area. The study's methodology is qualitative and field research type. Its participants were 25 students of the final year of program the aforementioned from a private institution of higher education located in the interior of São Paulo state. The disciplines selected for developing actions were: Methodology of Physical Education in Basic Education II, Course Completion Seminar and Supervised Internship. The research results indicate that the use of cases in the Physical Education course provides both the professor and the students with results that are positive and necessary for their professional performance. Also, when teaching is developed in a committed way and from a critical and reflective pedagogical practice by means of exciting challenges, both the professor and the students achieve positive results. For this, professors need to extricate themselves from the routine and the "comfort zone" afforded by class lectures and classes rooted in traditional methodologies.
\end{abstract}

\section{Keywords}

Physical education - Case-based learning - Higher education.

I- Centro Universitário UNIFAFIBE, Bebedouro, SP, Brasil.

Contact:acmetzner@hotmail.com

II- Translator's note: In Brazil, basic education comprises early childhood, primary and secondary education. 


\section{Introdução}

A docência, durante muito tempo, foi concebida como um dom ou vocação. Ou seja, as pessoas que gostavam e tinham facilidade para ensinar tornavam-se professores. Hoje, sabemos que a docência vai muito além do gostar de ensinar e do domínio dos conteúdos de suas matérias de ensino. Os desafios atuais da docência requerem conhecimento científico e prático. Trata-se da necessidade do docente estar em constante formação, ser capaz de cumprir as exigências das instituições de ensino, atender as necessidades e expectativas dos alunos, ter criatividade para trabalhar com turmas heterogêneas e saber lidar com as diferenças, conseguir articular diferentes conteúdos, acompanhar os avanços tecnológicos, cumprir o programa de ensino, aliar ensino e pesquisa etc.

0 exercício da docência nunca é estático ou permanente. Segundo Cunha (2004, p. 526), "a docência é um processo que se constrói permanentemente, aliando o espaço da prática com o da reflexão teorizada”. As novas informações, as pesquisas, os alunos, as diferentes instituições de ensino modificam a forma de o professor ministrar as suas aulas.

Dessa forma, visando a garantir a qualidade do ensino e a aprendizagem efetiva dos alunos, o professor do ensino superior precisa articular os conteúdos de sua disciplina com os das demais disciplinas do curso.

A prática pedagógica no ensino superior necessita superar a visão de ensino fragmentado, transformando as partes em um todo significativo. 0 primeiro passo é estabelecer interconexões entre as disciplinas do curso; em seguida, permitir a interconexão dos conteúdos, buscando a unifıcação do conhecimento. Esses dois fatores são denominados interdisciplinaridade e transdisciplinaridade, respectivamente.

0 termo interdisciplinaridade pode ser entendido como um conjunto de disciplinas interligadas, ou seja, o conteúdo e as atividades desenvolvidas nas disciplinas que compõem a grade curricular de um curso não podem ser vistas de forma isolada ou fragmentada. A interdisciplinaridade "surgiu nos anos 70 como resposta às necessidades de uma abordagem mais integradora da realidade". (DENCKER, 2002, p. 19). De acordo com Martinazzo (2010, p. 203):

[...] a interdisciplinaridade caracterizase por uma comunicação e até mesmo por uma colaboração entre as diferentes disciplinas, mantendo-se, porém, cada uma com e em sua especificidade.

Em relação à transdisciplinaridade, podemos dizer que existia a mesma busca da unidade do conhecimento para que os alunos tenham uma visão mais ampla e global dos fenômenos estudados, visando a formar profissionais cada vez mais completos. Ou seja, é a soma e unificação de todos os saberes.

A compreensão transdisciplinar rompe com a forma epistemológica e metodológica tradicional de ensino. Os limites parcelares impostos pelas disciplinas tradicionalmente organizadas fragmentam o conhecimento e impedem a compreensão de um sistema complexo, no qual todos os elementos estão em relação e interdependência. (MARTINAZZO, 2010, p. 201)

0 autor complementa que, para a compreensão da realidade, é necessária uma abordagem transdisciplinar, visando à quebra da divisão e hierarquização de conhecimentos, bem como à transposição dos conhecimentos estanques e à promoção do diálogo entre as diferentes disciplinas.

As disciplinas de um curso superior são organizadas de forma semestral ou anual. $\mathrm{Na}$ grade curricular, encontramos nos primeiros semestres as disciplinas consideradas como pré-requisitos e as demais disciplinas são distribuídas ao longo do curso. Acreditamos que geralmente as disposições dessas disciplinas são feitas a partir de uma reflexão sobre a importância de manter uma integração entre elas. 
Porém, uma boa organização da grade curricular de um curso não é suficiente para promover a inter e a transdisciplinaridade, pois é preciso desenvolver práticas curriculares que possibilitem a compreensão das relações existentes entre as diferentes disciplinas.

Os empecilhos à não-fragmentação do currículo em disciplinas são variados, abrangem o desconhecimento do significado de projetos, a falta de formação específica para trabalhar com os mesmos, a acomodação pessoal e coletiva, até o medo de perder o prestígio pessoal, pois a interdisciplinaridade leva ao anonimato - o trabalho individual anula-se em favor de um objetivo maior - o coletivo. (FAZENDA, 1993, p. 42)

Além disso, a autora aponta que é mais fácil trabalhar de forma fragmentada do que discutir ideias. Todo esse comodismo acaba deixando os projetos interdisciplinares e transdisciplinares elaborados pelas universidades apenas no papel.

0 conhecimento não pode se restringir apenas a uma área específica, mas, sim, deve-se articular o conhecimento de uma disciplina com os saberes e práticas das demais. Isso estreitará as fronteiras existentes entre as disciplinas de um curso e construirá eixos de ligação entre elas, proporcionando a reunificação do conhecimento.

Segundo Almeida (2012, p. 158):

[...] é a partir deste momento que começa ganhar força o desenvolvimento de propostas de trabalho integradoras e a ser destacada a importância do trabalho coletivo que possibilita comunicação entre as disciplinas.

Dentre essas propostas, podemos citar a aprendizagem baseada em casos. Acreditamos que a utilização de casos no ensino superior é importante para formar profissionais capazes de estabelecer conexões entre as disciplinas, de lidar com o grande número de informações recebidas e com as situações reais a que são expostos no dia a dia da profissão.

Ao buscar resoluções para o caso apresentado, os alunos organizam as suas ideias, buscam conhecimentos teóricos e práticos nas diferentes disciplinas, apresentam soluções, executam na prática a solução proposta, visando a verificar a sua aplicabilidade e pertinência etc.

Nesse contexto, o presente artigo tem como objetivo apresentar uma proposta de trabalho, estruturada a partir da aprendizagem baseada em casos, implementada em um curso de licenciatura em educação física de uma instituição particular de ensino superior.

\section{A educação física no ensino superior: alguns apontamentos}

A educação física, segundo Figueiredo (2004, p.90), “pode ser compreendida como área que tematiza/aborda as atividades corporais em suas dimensões culturais, sociais e biológicas". Assim, o campo de atuação e os conteúdos da educação física são muito amplos.

No passado, os cursos de licenciatura em educação física estavam preocupados em:

[...] formar executores e repetidores de habilidades motoras sem o devido conhecimento sobre motricidade humana e sem comprometimento com o processo educacional. Por isso, as disciplinas curriculares que compunham estes cursos valorizavam excessivamente a prática de habilidades como um fim em si mesmas. (GHILARDI, 1998, p. 9)

Hoje, saber executar bem determinada habilidade não é garantia de ser um bom profissional, pois, para atuar na área de educação física, é necessário muito mais do que saber-fazer. Pelo contrário, é fundamental o domínio de um conjunto de conhecimentos práticos e teóricos, bem como ser capaz de justificar as suas atitudes a partir do conhecimento científico (GHILARDI, 1998). 
Por isso, os currículos dos cursos de formação, que historicamente priorizaram a transmissão de conteúdos, precisam ser questionados, pois os cursos que possuem uma visão conteudista geram disciplinas fragmentadas. Essa fragmentação existente colabora com a hierarquia de saberes disciplinares, ou seja, algumas disciplinas são mais valorizadas ou têm mais credibilidade dentro de um curso.

Nos cursos de educação física, as disciplinas mais temidas ainda são a fisiologia, anatomia e cinesiologia. 0 medo e a dificuldade que muitos alunos encontram ao cursarem tais disciplinas criam um falso conceito de que essas são as mais importantes do curso.

Na verdade, não há disciplinas melhores ou piores, mais ou menos importantes dentro de uma grade curricular. Todas as disciplinas fazem parte de um único curso superior e, portanto, devem caminhar juntas em um mesmo patamar.

Por isso, de acordo com Neira (2010, p.73) "o currículo precisa ser fruto de uma ação coletiva”. 0 autor complementa dizendo que "os saberes e situações que constituem o currículo da formação para a docência refletem, em última análise, o sujeito-professor que se quer formar" (p.74). Ao contrário de um novelo de lã todo emaranhado, o currículo precisa ter o formato de um quebra-cabeça onde todas as "peças" (disciplinas) se encaixam e dialogam entre si.

Neira (2010, p.89) acredita que os currículos dos cursos de formação inicial de professores de educação física necessitam de modificações, como "alternativa para o desenvolvimento de uma identidade profissional docente coerente com as necessidades educativas da contemporaneidade".

Para Martins, Moreira e Simões (2006), devemos ensinar aos alunos de educação física em sua formação acadêmica:

[...] a associação entre o ver, o ser, o fazer, o conhecer, o compreender e o conviver, ou seja, uma formação que venha a permitir uma ação profıssional que respeite o princípio da rigorosidade, que esteja em sintonia com o contexto sócio-histórico-cultural de seus alunos e especialmente, que incorpore o entendimento da complexidade humana. (MARTINS; MOREIRA; SIMÕES, 2006, p. 187)

0 Conselho Nacional de Educação (Parecer 009/2001, p. 10) aponta que os cursos de licenciatura devem evidenciar:

[...] os problemas e as especificidades das diferentes etapas e modalidades da educação básica, estabelecendo o equilíbrio entre o domínio dos conteúdos curriculares e a sua adequação à situação pedagógica.

Para alcançar tais metas, Hunger e Ferreira (2006, p. 145) acreditam que é necessário:

[...] conceber a aprendizagem como um processo que depende da interação entre o indivíduo e o meio a partir de uma perspectiva metodológica que enfoque situações-problemas e o desenvolvimento de projetos interdisciplinares.

Os cursos voltados à formação de professores, assim como a estrutura curricular, não podem ser pensados de forma isolada e desconectada. Por isso, é necessário discutirmos e refletirmos a respeito de questões relacionadas às contribuições das metodologias problematizadoras no ensino superior, especialmente nos cursos de licenciatura em educação física, visando à melhoria da qualidade desses cursos de graduação, tanto na dimensão profissional quanto na acadêmica.

\section{Aprendizagem baseada em casos}

As chamadas metodologias problematizadoras têm sido bastante divulgadas mundialmente, dentre elas encontramos a case based learning ou aprendizagem baseada em casos, também conhecida por estudo de casos. 
Em relação à aprendizagem baseada em casos (ABC), Montanher (2012, p. 6) aponta que é:

[...] uma estratégia de ensino e de aprendizagem ativa, contextualizada e centrada no aluno, em que o ensino se dá a partir de um Caso paradigmático que contextualiza uma situação problematizadora. Nesse modelo o professor desempenha o papel de mediador do processo de aprendizagem, questionando e orientando os alunos a refletir, pesquisar, analisar e formular hipóteses sobre o Caso e os problemas conexos a este, de forma colaborativa e dialógica.

0 autor complementa dizendo que esse processo fundamentado no questionamento é essencial para motivar a aprendizagem de novos conteúdos e a construção de novos saberes.

0 Caso seria o instrumento que possibilitaria mobilizar o conhecimento-em-ação dos alunos, conhecimento este que os leva a agir de certa forma em certas situações, sem ter plena consciência dos conceitos envolvidos nos bons resultados obtidos. Ao observar os alunos trabalharem com o Caso, o professor teria possibilidade de reconhecer neste conhecimento-em-ação os seus saberes prévios, o que é de grande valia, uma vez que possibilitaria orientar o ensino com base nestes dados. (MONTANHER, 2012, p. 9)

Os casos podem basear-se em problemas reais ou fictícios. 0 importante é fazer com que o aluno interaja com o problema, formule hipóteses, tome decisões e reflita sobre os resultados, favorecendo uma participação ativa no processo de ensino e aprendizagem.

Caracteristicamente, um caso, segundo Reis e Linhares (2008, p. 231):

[...] deve se constituir uma questão a ser resolvida no formato livre ou aberta; deve ser atual e de interesse dos aprendizes, propiciando ligações com contextos da vida: sociais, culturais, econômicos, ambientais, profissionais etc.

Os autores complementam dizendo que esses casos podem ser longos ou curtos dependendo do objetivo do estudo.

Destarte, o caso pode ser elaborado a partir de diversos contextos, porém não se deve perder o foco principal, que é promover o desenvolvimento e aperfeiçoamento do conhecimento do aluno, no sentido de desenvolver no futuro profissional competências e habilidades necessárias para a sua formação.

Outro ponto relevante na aprendizagem baseada em casos é que o papel do professor está relacionado ao mesmo tempo com a escolha ou elaboração dos casos e com todo processo de discussão.

Christensen e Hansen (1987 apud Montanher, 2012, p. 35) argumentam que:

[...] a liderança do processo de discussão do Caso é uma responsabilidade crítica do professor, o qual, mais que possuir um conhecimento profundo do campo ou problema colocado no Caso, deve procurar mediar o processo pelo qual os alunos individualmente, e em grupo, exploram a complexidade da situação específica apresentada pelo Caso.

A aprendizagem baseada em casos permite integrar informações provenientes de diferentes disciplinas e de diferentes campos do conhecimento. Além disso, a aplicação dessa metodologia problematizadora permite ao professor pensar e planejar todas as etapas, considerar os alunos (perfil), os tempos e prazos, os materiais didáticos ou fontes, os objetivos de aprendizagem e a sua avaliação, a interação entre professor/alunos e alunos/alunos; enfim, ela permite ao professor traçar uma hipótese de trabalho, que poderá ser adaptada e alterada ao longo do curso ou disciplina.

Para isso, o professor precisa desvencilhar-se da rotina e da zona de conforto 
propiciada pelas aulas expositivas e enraizadas pelas metodologias tradicionais.

Hoje, diante de tantos avanços tecnológicos e do rápido acesso às informações, é notória a necessidade de o professor tornar a sua aula motivadora. A aprendizagem baseada em casos pode ser considerada uma alternativa plausível, devido à sua aproximação com a realidade e com o preparo para a vida profissional dos alunos.

Acreditamos que, mesmo que tenhamos um sólido embasamento conceitual relacionado à aprendizagem baseada em casos, somente se o colocarmos em ação, em nossa prática, é que conseguiremos dar significado a esses conceitos e reelaborá-los. Por isso, a seguir, apresentaremos um caso aplicado em um curso de licenciatura em educação física.

\section{Metodologia}

Estudar os conteúdos de uma determinada disciplina e relacioná-los com os das demais presentes no curso para solucionar um caso é muito mais significativo e produtivo para o aluno do que apenas estudar esse conteúdo para a realização de uma prova. Por isso, acreditamos que a utilização da aprendizagem baseada em casos é importante para a formação no ensino superior.

Para a elaboração do caso, o primeiro passo foi pensarmos no conhecimento prévio dos alunos do curso de licenciatura em educação física e nas disciplinas que estavam sendo ministradas naquele semestre, visando a unir informações que envolviam os conteúdos abordados nessas disciplinas. Além disso, procuramos um tema motivador, que despertasse o interesse dos alunos.

0 caso elaborado foi o seguinte:

Maria, empregada doméstica há 10 anos, tem 40 anos, é casada e mãe de 3 filhos. Moradora de um bairro periférico de um município do interior de São Paulo, sai de casa às $06 \mathrm{~h} 30 \mathrm{~min}$ e retorna por volta das $18 \mathrm{hs}$.
0 filho mais velho, Guilherme, tem 15 anos e está cursando o primeiro ano do ensino médio. Já o Carlos tem 8 anos e está no ensino fundamental. E o caçula, Joãozinho, tem 4 anos e está na educação infantil. Todos estão matriculados em escolas públicas.

No final de semana, Maria gosta de conversar com os filhos sobre o que fizeram na escola, o que aprenderam, do que mais gostaram, como estão se comportando na sala de aula etc. E então, nesse dia, conversa vai e conversa vem, surgiu o papo sobre as aulas de educação física.

Guilherme disse que o professor de educação física dele é muito legal, pois deixa os meninos jogarem futebol $\mathrm{e}$ as meninas jogarem vôlei em todas as aulas. Isso é muito bom, pois, segundo Guilherme, as meninas só atrapalham quando inventam de querer praticar esse esporte, pois futebol é coisa de menino.

Carlos relatou que não gosta de participar das aulas de educação física; ele prefere ficar sentado olhando os colegas. 0 professor não insiste para ele participar das aulas, pois ele prefere trabalhar apenas com aqueles alunos que "estão a fim de aprender". Carlos só participa da aula de educação física quando chove, pois ele gosta de jogar damas e, sempre que está chovendo, o professor deixa os alunos dentro da sala de aula jogando damas e jogo da velha.

Já o Joãozinho disse que na escola dele não tem professor de educação física e que é a tia da sala que leva as crianças para o parque ou dá umas bolas e bambolês para brincarem no pátio.

Após essa conversa, Maria ficou preocupada, pois os três filhos estão acima do peso e gostaria que eles se interessassem por alguma atividade física, pois ela já assistiu várias reportagens na TV sobre os benefícios da atividade física para a saúde e qualidade de vida. Porém, nos finais 
de semana e no tempo livre, as crianças preferem ficar assistindo à televisão ou jogando videogame.

Maria até entende as crianças, pois no bairro onde mora não há nenhum local para brincar. As praças estão destruídas, não há campo ou quadra para praticar esportes e, além disso, o bairro é muito violento.

Na segunda-feira de manhã, Maria ainda estava inquieta, pensando no que havia conversado com os filhos no final de semana. Então, ao chegar à casa dos patrões, decidiu perguntar para um dos filhos do casal sobre como eram as suas aulas de educação física.

Maria procurou Gabriel para falar sobre o assunto. Gabriel tem 8 anos e estuda em uma escola particular localizada no centro da cidade. 0 menino disse que, na aula passada, o professor de educação física decidiu realizar uma atividade de resgate de brinquedos e brincadeiras tradicionais. A primeira parte dessa atividade foi fazer uma entrevista com os pais sobre as brincadeiras que fizeram parte da sua infância. Curiosamente, o brinquedo mais citado foi o "pé de lata". A partir desse resultado, o professor propôs aos alunos que confeccionassem os seus brinquedos utilizando os materiais recicláveis encontrados em casa. A etapa posterior foi realizar, no gramado da escola, uma corrida utilizando os pés de lata. Foi muito divertido. 0 professor disse que, na próxima aula, iremos confeccionar bolas de meia para jogar queimada. Acho que vai ser legal também.

No final da conversa, diante de tanta contradição, Maria questionou: Por que as aulas de educação física são tão diferentes? É culpa dos professores ou da escola? Será que os professores de educação física que atuam em escolas particulares são melhores do que os das escolas públicas? Quais são os principais conteúdos trabalhados nas aulas de educação física? A disciplina de educação física é realmente necessária no currículo da educação básica?

Após a elaboração do caso, foram planejadas e organizadas ações para serem desenvolvidas nas disciplinas de metodologia da educação física na educação básica, seminário de conclusão de curso e estágio supervisionado, visando à integração entre os conteúdos abordados e as reflexões para a resolução do caso apresentado.

Quadro 1 - Proposta de atividades/conteúdos relacionando as situações-problema que serão desenvolvidos na disciplina

\begin{tabular}{|c|c|}
\hline Disciplina & Proposta de atividade/conteúdos \\
\hline $\begin{array}{l}\text { Metodologia da } \\
\text { educação física na } \\
\text { educação básica }\end{array}$ & $\begin{array}{l}\text { - Impactos da Lei de Diretrizes e Bases da Educação Nacional na Educação Física escolar (LDBEN n. 9394/96). } \\
\text { • Parâmetros Curriculares Nacionais para a Educação Física (PCN's). } \\
\qquad \text { Cultura Corporal de Movimento. } \\
\text { • Discussão sobre a importância da criatividade nas aulas de educação física nos diferentes níveis de ensino. } \\
\text { • Debate sobre as seguintes questões: de que forma o professor poderia motivar os alunos a participarem das aulas } \\
\text { de educação física, principalmente, no ensino médio? Por que, geralmente, as aulas de educação física, ministradas } \\
\text { em instituições particulares de ensino são tão diferentes daquelas das escolas públicas? }\end{array}$ \\
\hline $\begin{array}{c}\text { Seminário de } \\
\text { conclusão de curso }\end{array}$ & $\begin{array}{l}\bullet \text { Levantamento de problemas de pesquisa a partir do contexto apresentado. } \\
\bullet \text { Trabalho escrito: propostas de pesquisas (tema, objetivo, justificativa, método). } \\
\bullet \text { Apresentação das propostas. } \\
\bullet \text { Discussão sobre as propostas apresentadas. }\end{array}$ \\
\hline $\begin{array}{c}\text { Estágio } \\
\text { supervisionado }\end{array}$ & $\begin{array}{l}\text { - Os alunos deverão, a partir dos estágios realizados, comparar a situação-problema com a realidade vivenciada no } \\
\text { âmbito escolar. } \\
\text { - Discussão sobre diferentes formas de minimizar e/ou solucionar os problemas apresentados com base nos } \\
\text { conteúdos teóricos estudados nas diferentes disciplinas. }\end{array}$ \\
\hline
\end{tabular}

Fonte: Dados da pesquisa 
Os conteúdos e atividades propostas em cada disciplina, apresentados no quadro 1 , foram desenvolvidos em uma turma de 25 alunos do último ano do curso de licenciatura em educação física pertencentes a uma instituição particular de ensino superior, localizada no interior do estado de São Paulo.

As discussões e debates ocorridos nas disciplinas foram gravados e serviram de referência para a coleta de dados, proporcionando um registro detalhado das falas dos participantes da pesquisa.

\section{Resultados e discussão:}

metodologia da educação física na educação básica

Na disciplina de metodologia da educação física na educação básica, realizamos com os alunos uma discussão a respeito da importância da criatividade nas aulas de educação física nos diferentes níveis de ensino. Dentre os principais comentários, encontramos:

- É importante ser criativo nas aulas de educação física para dinamizar as aulas, modificar as formas de aprendizado, conseguir atingir a maior parte dos alunos, conquistando a participação de todos pelo prazer.

- A criatividade é importante para adaptar os materiais e a aula de acordo com o espaço disponível.

- Como a falta de recursos é muito comum, principalmente nas escolas públicas, o professor de educação física precisa ser criativo para conseguir diversificar a sua aula.

- A criatividade é importante para fazer com que os alunos sempre tenham interesse pela aula e para que o professor seja capaz de adequar o conteúdo de acordo com a sua faixa etária.

Os participantes da pesquisa acreditam que ser criativo é fundamental para a atuação do professor de educação física, devido principalmente à falta de recursos e à necessidade de motivar a participação dos alunos por meio de atividades diferenciadas.

Segundo Wechsler (1998, p. 40), por meio da criatividade, é possível:

[...] identificar as dificuldades ou os elementos faltantes; formular hipóteses a respeito das deficiências encontradas; testar e retestar essas hipóteses e, por último, comunicar os resultados encontrados.

Por meio da criatividade, o professor é capaz de transpor as dificuldades que o contexto educacional apresenta diariamente nas escolas e criar novas oportunidades para que os alunos vivenciem espaços, materiais, atividades e situações diversas.

Após o término da discussão acerca da criatividade nas aulas de educação física, iniciamos um debate sobre as seguintes questões: de que forma o professor poderia motivar os alunos a participarem das aulas de educação física, principalmente no ensino médio? Por que, geralmente, as aulas de educação física ministradas em instituições particulares de ensino são tão diferentes das escolas públicas?

De acordo com os participantes da pesquisa, para motivar a participação dos alunos nas aulas de educação física, o professor precisa diversificar os conteúdos e inovar as suas estratégias de ensino.

É importante ressaltar que os conteúdos da educação física escolar têm como centro a cultura corporal de movimento. De acordo com Soares et. al (1992, p. 38), cultura corporal pode ser definida como:

[...] acervo de formas de representação do mundo que o homem tem produzido no decorrer da história, exteriorizadas pela expressão corporal: jogos, danças, lutas, exercícios ginásticos, esporte, malabarismo, contorcionismo, mímica e outros, que podem ser identificados como formas de 
representação simbólica de realidades vividas pelo homem, historicamente criadas e culturalmente desenvolvidas.

Diversos são os conteúdos possíveis de trabalhar nas aulas de educação física escolar. Porém, a não diversificação desses conteúdos nos diferentes níveis de ensino, segundo Silva e Sampaio (2012, p. 116), podem causar sérios prejuízos:

[...] tanto no que tange a restrição ao acesso à cultura produzida pela sociedade no período de escolarização quanto à sua vivencia após a etapa de formação, fator que pode contribuir negativamente nas atitudes a serem tomadas frente à ocupação do tempo disponível com o lazer e na compreensão da importância para a saúde e qualidade de vida advindas da Cultura Corporal do Movimento.

Por isso, a educação física enquanto componente curricular da educação básica não precisa restringir as experiências corporais nas aulas apenas a um tipo de conteúdo. Pelo contrário, necessita possibilitar o acesso aos diversos conteúdos da cultura corporal de movimento.

Em relação à diferença entre as aulas ministradas em instituições públicas e privadas, os participantes acreditam que os fatores que contribuem para que os professores de educação física ministrem aulas de maior qualidade nas instituições particulares são: melhor infraestrutura; grande quantidade e diversidade de materiais; número reduzido de alunos por sala; os professores são constantemente avaliados pela direção da escola; existe uma cobrança maior dos pais dos alunos; e os professores são mais bem remunerados.

Embora tenhamos atingido atualmente altos índices de universalização da oferta do ensino fundamental, a qualidade do ensino desenvolvido em nossas escolas encontra-se em situação crítica. Assim, a construção de uma escola pública dos anos iniciais democrática, inclusiva, crítica, reflexiva e de qualidade para todos é ainda um enorme desafio. (LIMA, 2012, p. 152)

As dificuldades que os professores de educação física encontram nas escolas públicas são visivelmente maiores do que as encontradas nas instituições particulares de ensino. Por exemplo, a falta de apoio do poder público, atrelado à má remuneração e condições de trabalho, levam o professor a ministrar uma aula de baixa qualidade nas escolas públicas.

As políticas públicas destacam a necessidade da melhoria da qualidade do ensino. Porém, existe uma enorme fenda entre o discurso político e a realidade educacional. Os professores, mesmo reorganizando a sua prática e utilizando diferentes estratégias de ensino, não são capazes, sozinhos, de alcançar a qualidade almejada pela legislação. Por isso, os pontos que dificultam o trabalho do professor nas escolas públicas não podem ser deixados de lado.

Segundo Fugikawa (2004), para que as ações implementadas pelos professores de educação física sejam significativas e voltadas para a construção da cidadania e emancipação do educando, o trabalho do professor precisa estar coerente com as especificidades dos diferentes níveis de ensino e com a prática que se pretende implantar na sala de aula. Mas, a autora complementa que

[...] isso implica também salários, planos de carreira dignos e condições ideais de trabalho com relação ao material de apoio didático, por exemplo. (FUGIKAWA, 2004, p. 32)

\section{Seminário de conclusão de curso}

Os participantes, a partir do caso apresentado, levantaram algumas questões de pesquisa que poderiam ser abordadas no Trabalho de Conclusão de Curso (TCC). Dentre elas: 
- Qual a importância do professor de educação física na educação infantil?

- Quais as dificuldades encontradas pelos professores de educação física em inovar e/ ou modificar as suas aulas?

- Por que a maioria dos alunos do ensino médio não gosta de participar das aulas de educação física?

- Qual a importância do resgate de jogos

e brincadeiras tradicionais nas aulas de educação física?

As questões de pesquisa apontadas pelos alunos estão de acordo com os problemas apresentados no caso: a necessidade da inserção do professor de educação física na educação infantil; as dificuldades que os professores encontram em diversificar os conteúdos e motivar a participação dos alunos; a importância de trabalhar com os jogos e brincadeiras tradicionais nas aulas de educação física.

Apesar de encontrarmos na literatura diversas pesquisas a respeito dessas questões, é importante intensificarmos os estudos que envolvem esses temas, principalmente, durante os cursos de licenciatura em educação física, visando a ampliar os conhecimentos teóricos e científicos dos graduandos.

Segundo Paiva e Betti (2010), vários estudos surgiram no âmbito da educação física escolar após a década de 80 , contudo:

[...] ainda há carência de pesquisas que, dotadas de qualificação teórico-metodológica, busquem o confronto dessas novas proposições com situações reais no âmbito escolar, para que se possam avaliar criticamente suas potencialidades e limitações, de modo a servir, com maior nitidez, como orientação e referência aos professores. (PAIVA; BETTI, 2010, p. 305)

Ao permitirmos e incentivarmos os alunos a desenvolverem pesquisas envolvendo o processo de ensino e aprendizagem, bem como os obstáculos encontrados pelo professor no dia a dia escolar, estamos oferecendo aos futuros professores um referencial para a sua atuação profissional.

\section{Estágio supervisionado}

A partir dos estágios realizados, os alunos compararam o caso com a realidade vivenciada no âmbito escolar.

Os alunos apontaram que a realidade escolar é muito parecida com aquela da situação fictícia, pois: no ensino médio, a maioria dos professores ministra conteúdos envolvendo os esportes e os alunos não têm interesse em participar das aulas de educação física; no ensino fundamental, não há diversidade de conteúdos; e, na educação infantil, em grande parte das escolas, as atividades de movimento são ministradas pelos professores polivalentes (professores formados em pedagogia).

Acreditamos que a educação física precisa reconstruir a sua prática pedagógica tradicional e caminhar em busca de objetivos, conteúdos e metodologias adequadas aos diferentes níveis de ensino e pautadas na cultura corporal de movimento. De acordo com Fugikawa (2004, p.41), "a eficiência do processo de ensino depende da forma como a ação pedagógica é organizada e sistematizada pelo professor".

Para isso, o professor precisa "ter conhecimento (teórico-prático) para compreender a realidade em que o aluno está inserido, deve estar atento às peculiaridades que ocorrem e procurar instrumentalizar-se para intervir conscientemente no contexto das relações escolares." (FUGIKAWA, 2004, p. 32)

Em relação às formas de minimizar e/ ou solucionar os problemas atuais da educação física escolar, os alunos disseram que:

Os professores que atuam muito tempo dentro das escolas precisam ser incentivados a participar de cursos para atualizarem os seus conhecimentos; para isso, esses cursos precisam ser de qualidade e gratuitos. (Informante da pesquisa) 
Os alunos precisam sair da graduação preparados para lidarem com o dia-a-dia escolar; os professores de educação física precisam diversificar os conteúdos de suas aulas e motivar a participação dos alunos. (Informante da pesquisa)

É necessário melhorar o salário dos professores e as condições de trabalho; só assim o professor ministrará uma boa aula. (Informante da pesquisa)

As respostas giraram em torno de uma melhor formação acadêmica, diversificação e escolha adequada de conteúdos, formação continuada de qualidade para os professores, elaboração de planos de ensino procurando atender as necessidades dos alunos, melhores salários e condições de trabalho.

Acreditamos que, apesar de as políticas públicas não oferecerem suportes adequados para a melhoria das condições de trabalho e a valorização dos professores em efetivo exercício, os professores de educação física, apesar de todas as dificuldades, precisam buscar o desenvolvimento de um trabalho com qualidade, elaborando aulas de acordo com as necessidades dos alunos, adequando os materiais e espaços disponíveis, bem como buscando novos conhecimentos a partir da educação continuada.

\section{Mesa-redonda}

Após a discussão a respeito do caso nas diferentes disciplinas, convidamos três professores para participarem de uma mesa-redonda visando a discutir os temas abordados. Dentre esses professores, convocamos um ex-aluno do curso de licenciatura em educação física, o professor de uma das disciplinas trabalhadas naquele semestre e um professor de outra instituição de ensino superior, que desenvolve pesquisas no âmbito da educação física escolar.

A mesa-redonda teve duração de duas horas e foi importante para que os participantes da pesquisa visualizassem o resultado final do trabalho desenvolvido durante o semestre, comparassem a situação fictícia apresentada no caso com a realidade e as pesquisas atuais na área e, além disso, pudessem estabelecer interconexões entre os conteúdos das diferentes disciplinas que compõem a grade curricular do curso.

\section{Considerações finais}

Na busca de superar a fragmentação do ensino nos cursos de licenciatura em educação física, apresentamos uma proposta de trabalho a partir da aprendizagem baseada em casos. É importante ressaltar que esse é apenas um dentre muitos recursos que podem ser utilizados no ensino superior objetivando a formação integral dos alunos.

A docência, no ensino superior, quando é desenvolvida de forma comprometida e a partir de uma prática pedagógica crítica e reflexiva por meio de desafios instigantes, permite que tanto o professor quanto os alunos alcancem resultados positivos e desenvolvam habilidades necessárias para a sua atuação dentro e fora das universidades.

A clássica distorção entre teoria e prática ainda é comum em muitos cursos do ensino superior. Por isso, é necessário oferecer ferramentas para que os alunos pensem de forma global, possam planejar suas ações e atuar de forma ativa no processo de ensino e aprendizagem.

0 papel do professor é fundamental nesse caso, pois, para que novas metodologias, diferentes recursos tecnológicos, bem como o trabalho inter e transdisciplinar tragam resultados positivos, os professores necessitam trabalhar em parceria, oportunizando a integração entre áreas diferentes de conhecimento.

Esperamos que as sugestões apresentadas nesse artigo contribuam para o surgimento de novas ideias e ampliem as discussões pautadas nas questões referentes à aprendizagem baseada em casos nos cursos de licenciatura em educação física. 


\section{Referências}

ALMEIDA, Julio G. Interdisciplinaridade: significando o trabalho escolar em contextos metropolitanos. Revista Contrapontos Eletrônica, v. 12, n. 2, p.154-161, mai./ago. 2012.

BRASIL. Conselho Nacional de Educação. Parecer CNE/CP 009, de 08 de maio de 2001.

CUNHA, Maria Isabel. da. Diferentes olhares sobre as práticas pedagógicas no ensino superior: a docência e sua formação. Educação, Porto Alegre, v. 27, n. 3, p. 525-536, set./dez. 2004.

DENCKER, Ada F. M. Pesquisa e interdisciplinaridade no ensino superior: uma experiência no curso de turismo. São Paulo: Aleph, 2002.

FAZENDA, Ivani C. A. Integração e interdisciplinaridade no ensino brasileiro: efetividade ou ideologia. São Paulo: Loyola, 1993.

FIGUEIREDO, Zenólia C. C. Formação docente em educação física: experiências sociais e relação com o saber. Movimento, Porto Alegre, v. 10, n. 1, p. 89-111, jan./abr. 2004.

FUGIKAWA, Claudia S. L. Metodologia de ensino da educação física: repensando a ação do professor. 2004. 87f. Dissertação (Mestrado em Engenharia da Produção) - Universidade Federal de Santa Catarina, Florianópolis, 2004.

GHILARDI, Reginaldo. Formação profissional em educação física: a relação teoria e prática. Revista Motriz, v. 4, n. 1, p. 1-11, Jun. 1998.

HUNGER, Dagmar; FERREIRA, Lilian Aparecida. As diretrizes curriculares nacionais para os cursos de graduação em educação física e de licenciaturas. In: SOUZA NETO, Samuel; HUNGER, Dagmar (Orgs.). Formação profissional em educação física: estudos e pesquisas. Rio Claro: Biblioética, 2006. p. 141-146.

LIMA, Vanda M. M. A complexidade da docência nos anos iniciais na escola pública. Nuances: estudos sobre educação, v. 22, n. 23, p. 151-169, maio/ago. 2012.

MARTINAZZO, Celso J. 0 pensamento complexo e a educação escolar na era planetária. Revista Contrapontos - Eletrônica, v. 10, n. 2, p. 197-208, maio/ago. 2010.

MARTINS, Ida C.; MOREIRA, Wagner W.; SIMÕES, Regina. As novas diretrizes curriculares, a reestruturação curricular e o curso de educação física: a reformulação construída na UNIMEP. In: SOUZA NETO, Samuel; HUNGER, Dagmar (Orgs.). Formação profissional em educação física: estudos e pesquisas. Rio Claro: Biblioética, 2006, p. 187-194.

MONTANHER, Valter C. Aprendizagem baseada em casos nas aulas de física do ensino médio. 2012. 245f. Tese (Doutorado em Educação) - Universidade Estadual de Campinas, Campinas, 2012.

NEIRA, Marcos G. Quem estamos formando? Interpretando os currículos de licenciatura em educação física. In: CORREIA, Walter R.; CARREIRA FILHO, Daniel. Educação física escolar: docência e cotidiano. Curitiba: CRV, 2010. p. 69-91.

PAIVA, Bruna E.; BETTI, Mauro. A grande montanha de areia: breve encontro da educação física com a semiótica peirciana. In: LIMA, José M.; SILVA, José D.; RABONI, Paulo C. A (Orgs.). Pesquisa em educação escolar: percursos e perspectivas. São Paulo: Cultura Acadêmica, 2010. p. 303-314

REIS, Ernesto M.; LINHARES, Marília P. Desenvolvimento de uma ferramenta de organização e avaliação de fórum. In: SIMPÓSIO BRASILEIRO DE INFORMÁTICA NA EDUCAÇÃO (SBIE), Anais do..., 19, Fortaleza, 2004. Disponível em: <http://ceie-sbc.educacao. ws/pub/index.php/sbie/article/view/705/691 >. Acesso em: 07 maio 2013. p. 229-238.

SILVA, Junior V. P.; SAMPAIO, Tânia M. V. Os conteúdos da aulas de educação física do ensino fundamental: o que mostram os estudos? Revista Brasileira de Ciência e Movimento, v. 2, n. 20, p.106-118, 2012. 
SOARES, Carmen Lúcia et. al. Metodologia do ensino de educação física. São Paulo: Cortez, 1992.

WECHSLER, Solange M. Criatividade: descobrindo e encorajando. Campinas: PSY, 1998.

Recebido em: 16.06.2013

Aprovado em: 16.10.2013

Andreia Cristina Metzner é mestre em Educação pela Universidade Federal de São Carlos, professora dos cursos de Educação Física e Pedagogia do Centro Universitário UNIFAFIBE e professora de Educação Infantil da rede municipal de São Carlos. 